\title{
Fimbria-fornix lesions in young rats impair acquisition in a 14-unit T-maze similar to prior observed performance deficits in aged rats
}

\author{
ELAINE L. BRESNAHAN \\ Essex Community College, Baltimore, Maryland \\ and National Institute on Aging, Baltimore, Maryland
}

HIDEKI KAMETANI, EDWARD L. SPANGLER, and MARK E. CHACHICH

National Institute on Aging, Baltimore, Maryland

PHILIP R. WISER

Essex Community College, Baltimore, Maryland

and

DONALD K. INGRAM

National Institute on Aging, Baltimore, Maryland

\begin{abstract}
Bilateral electrolytic lesions were made in the fimbria-fornix of 3-month-old male Fischer-344 rats. One week after surgery, acquisition in a shock-motivated 14-unit T-maze was assessed in these experimental animals and compared with that of sham-operated and unoperated controls. All animals were pretrained to criterion in one-way active avoidance in a straight runway before receiving two 10-trial daily sessions in the complex maze task in which the response requirement was to negotiate each of five maze segments within $10 \mathrm{sec}$ to avoid footshock. All groups showed high levels of performance in pretraining. In the complex maze, rats sustaining damage to the fimbria-fornix exhibited learning impairments compared with controls in all analyzed performance measures including errors, run time, number of shocks, duration of shock, and alternation errors. The latter measure, which reflected the rat's tendency to maintain a strategy of alternating responses at the choice-points, showed no evidence of change with training among lesioned animals, whereas control animals demonstrated a dropout of this response strategy. The impairment in maze performance associated with the fimbria-fornix lesions appeared to parallel those previously observed in scopolamine-treated young rats and in aged rats.
\end{abstract}

It has been well documented that aged rodents, when compared with young adult counterparts, exhibit performance impairments in tasks involving learning within complex spatial environments such as a radial arm maze (Ingram, London, \& Goodrick, 1981), a circular platform task (Barnes, 1979; Barnes \& McNaughton, 1985), and a water maze (Rapp, Rosenberg, \& Gallagher, 1987). Relevant to the current investigation, several studies of rats and mice have demonstrated age-related performance impairment in a 14-unit T-maze (Goodrick, 1968, 1973; Ingram, 1985; Ingram, Spangler, Freeman, \& Richards, 1984; Ingram, Weindruch, Spangler, Freeman, \& Walford, 1987; Michel \& Klein, 1978; Walovitch, Ingram, Spangler, \& London, 1987). In this complex maze, con-

The authors acknowledge the valuable contributions of Gunther Baart, Richard Hiner, Maurice Zimmerman, and Raymond Bannar for construction of apparatus; Paul Ciesla for computer-generated figures; and Nancy Muth for histological assistance. The National Institute on Aging is fully accredited by the American Association for the Accreditation of Laboratory Animal Care. Address correspondence to Donald K. Ingram, Gerontology Research Center, National Institute on Aging, 4940 Eastern Avenue, Baltimore, MD 21224. secutive spatial discriminations, a left or right turn at each of 14 choice-points, are required for task solution. This paradigm has provided a robust demonstration of age differences in acquisition by laboratory rodents. Such agerelated impairment in this task has been evidenced with procedures that vary in distribution of practice and type of motivation (food, water, or footshock) and has been observed in several rodent genotypes, including Wistar rats, Fischer-344 rats, C57BL6/J mice, and C3B10RF1 mice (Ingram, 1985; Ingram et al., 1987; Walovitch et al., 1987).

Neurobiologists have attempted to link behavioral observations of age-related impairment in learning and memory performance to dysfunction observed in several neurotransmitter systems, including cholinergic, noradrenergic, serotonergic, and neuropeptide systems. The cholinergic system has received considerable attention with regard to geriatric memory dysfunction (Bartus, Dean, Beer, \& Lippa, 1982; Collerton, 1986; Coyle, Price, \& DeLong, 1983). Reduction of cholinergic markers, such as the loss of cholinergic neurons in the basal forebrain and decreased choline acetyltransferase activity 
in the cortex and hippocampus, appears to be correlated with a decline in memory function in patients with senile dementia of Alzheimer type, in normal aged humans, and in animals (Bartus et al., 1982). Thus, cholinergic involvement has been implicated as a critical factor mediating age-related learning and memory deficits (Bartus et al., 1982).

Consistent with a cholinergic hypothesis of geriatric memory dysfunction (Bartus et al., 1982), considerable research has demonstrated that the effects of cholinergic antagonists upon memory in young subjects appear to parallel those in aged subjects. Bartus (1978) found that scopolamine, a muscarinic receptor antagonist, given to young monkeys resulted in memory deficits parallel to those of aged monkeys in a delayed response task, and Bartus, Dean, and Beer (1983) found that physostigmine, an anticholinesterase compound, improved performance. Similarly, in the shock-motivated 14-unit T-maze, Spangler, Rigby, and Ingram (1986) recently reported that scopolamine impaired performance of young rats, a finding that also is similar to the performance deficit observed among aged rats in this particular task. Results from studies of fetal neural grafting provide evidence to support the involvement of the septohippocampal cholinergic system in age-related memory impairment. F. $\mathrm{H}$. Gage and Bjorklund (1986) reported that cholinergic-rich transplants of fetal septal cells attenuated an age-related deficit in water maze performance that could be manipulated by cholinergic agents.

Experimentally induced lesions of central cholinergic systems in young animals also have been found to produce deficits in many learning and memory tasks that resemble those observed in aged animals (Bartus et al., 1982; Bartus, Dean, Pontecorvo, \& Flicker, 1985). For example, lesions that interfere with cholinergic innervation of the hippocampus via the fimbria-fornix (FF) pathway disrupt learning and memory performance of young rats in a radial arm maze (e.g., Jarrard, 1978; Olton, Walker, \& Gage, 1978). Lesions of the medial septal nucleus disrupt performance in a radial arm maze and a water maze, which involve spatial learning (Miyamoto, Kato, Narumi, \& Nagaoka, 1987). Thus, the lesion data in young animals provide evidence of the involvement of the septohippocampal cholinergic system in spatial learning and memory tasks (Mitchell, Rawlins, Steward, \& Olton, 1982).

Olton, Becker, and Handelmann (1980) suggested a major role of the septohippocampal system in those tasks emphasizing a particular component of memory processing systems, that is, working memory. According to this conceptual framework, working memory is a trialdependent, temporary store of stimulus-response associations represented by memory for the arms that have been visited in the radial arm maze task or in other similar paradigms. In contrast to disruptive effects on working memory, FF lesions are not expected to interfere with trial-independent memory, such as that pertaining to which arms always remained unbaited in a radial maze. Such invariant aspects of task requirements reflect utilization of what is termed a reference memory store. This working memory/reference memory theory of hippocampal function then predicts that rats with FF lesions will perform well in tasks that heavily tax reference memory with little demand on working memory (Walker \& Olton, 1984). Knowlton, Wenk, Olton, and Coyle (1985) classified the 14-unit T-maze as a reference memory task, one that taxes trial-independent memory. They examined performance effects of combined lesions to the nucleus basalis magnocellularis and the medial septal nucleus of young rats in both the 14-unit T-maze and a radial arm maze. No performance impairment was observed in the 14-unit $T$-maze following this disruption of cholinergic input to both frontal neocortex and hippocampus, but performance impairment was reported in the radial maze.

The present experiment was conducted to assess effects of FF lesions in young rats upon acquisition in the 14unit T-maze to determine possible similarity to the previously observed age-related impairment. Moreover, consideration relative to cholinergic involvement in this task was given to the apparent discrepent results between the scopolamine study (Spangler et al., 1986) and the basal forebrain lesion study (Knowlton et al., 1985) relative to cholinergic involvement in this task. Lesions to the FF were selected to interrupt both hippocampal afferents and efferents.

\section{METHOD}

\section{Subjects}

Twenty-six 3-month-old male Fischer-344 rats weighing 250-300 g were obtained from Harlan Sprague-Dawley (Indianapolis, IN). Housed 2 per metal cage (Wahmann), these rats were allowed free access to water and food (NIH-07 diet formula) and were kept on a 12:12-h light:dark cycle (light on at $0600 \mathrm{~h}$ ). Initially, rats were randomly assigned to three groups: FF lesion, shamoperated control, and unoperated control.

\section{Apparatus}

Straight runaway. Pretraining consisted of one-way active avoidance conditioning in a clear Plexiglas straight runway (199.5 $\times 16.2 \times 16.7 \mathrm{~cm}$ ) with a grid floor made of diagonally placed stainless steel rods. The floor was wired in series to a Coulbourn Instruments (Model E13-08) shock unit, which provided constantcurrent scrambled shock. Identical startboxes and goalboxes were made of black Plexiglas $(24.8 \times 15 \times 15 \mathrm{~cm})$ with guillotine doors opening into the runway. The movable back wall of each box was fastened to a steel rod that was used to push the animal from the startbox into the runway. The boxes were interchangeable for start and goal positions. Thus, the animal was not handled during training. A mechanical timer, counter, and clocks were used to initiate shock after $10 \mathrm{sec}$, to record number of shocks, and to record duration of shock received, respectively. White noise was provided through a speaker located near the startbox.

14-unit T-maze. This maze, described elsewhere (Ingram, 1985; Spangler et al., 1986), is made of clear Plexiglas with a diagonally placed stainless steel grid floor wired in series to a Coulbourn Instruments shock unit (Model E13-08). The maze had 14 choicepoints, that is, 14 units divided into five segments with one gate 
after each segment and one gate between the start area and the first segment. The 10-sec shock-avoidance contingency in effect for each segment and the start area was controlled by a clock that was manually reset each time the animal crossed through a gate into the next segment. A black Plexiglas goalbox, identical to that used in pretraining, was placed in the goal area. Infrared photocells were located within each arm and cul-de-sac of the maze and were wired to a microprocessor that recorded beam interruptions and time between interruptions onto computer PROMS (Hamilton Avnet). Errors from the correct path, as previously defined by Goodrick (1968), and run times were scored on a VAX 11/780 computer. Masking noise was provided through four speakers positioned diagonally at each corner and facing the center of the maze. The maze was entirely surrounded by four wooden walls $(193.7 \times 211.45$ $\times 60.96 \mathrm{~cm}$ ) that were painted flat gray. The entire unit and the straight alley were located in a large room with overhead fluorescent lighting and with temperature maintained at $22^{\circ} \mathrm{C}$.

\section{Procedure}

Surgery. Animals were allowed 1 week of adaptation to our vivarium before surgery. On the day of surgery, the lesion and shamoperated rats were weighed, anesthetized with sodium pentobarbital, and given atropine sulfate before and penicillin after surgery. According to the rat brain atlas of Paxinos and Watson (1982), flat skull coordinates were determined for two lesion sites on each side of the midline. The anterior coordinates were $2.2 \mathrm{~mm}$ posterior to bregma, $2.6 \mathrm{~mm}$ lateral to midline, and $4.2 \mathrm{~mm}$ below the surface of the skull. Posterior coordinates were $3.0 \mathrm{~mm}$ posterior to bregma, $4.0 \mathrm{~mm}$ lateral to midline, and $4.6 \mathrm{~mm}$ below the surface of the skull. For both lesion and sham-operated animals, four holes were drilled in the skull at these coordinates, and the dura was cut beneath each hole. For lesion rats a $20-\mathrm{sec} 1.5-$ or $2.0 \mathrm{~mA}$ current from a Grass Model DC-LM 5 Lesion Maker was passed through one strand of a twisted and Teflon-insulated nichrome wire that was scraped approximately $0.5 \mathrm{~mm}$ at the tip. The wire electrode was not lowered below the dura in the sham-operated animals. Following surgery, all animals were allowed 1 week of recovery before receiving 3 days of pretraining and 2 days of maze training. Once maze training was completed, animals were sacrificed, and the dissected brains were stored in $10 \%$ formalin for histological analysis.

Straight runway pretraining. A 20 -min period of adaptation to the maze room preceded one-way active avoidance pretraining. For the first trial, the animal was taken from its cage and placed onto the grid floor in the startbox. The animal had $10 \mathrm{sec}$ to avoid footshock by running into the goalbox at the opposite end of the runway. Animals failing to enter the goalbox within $10 \mathrm{sec}$ received 0.8-mA scrambled footshock that continued until the rat entered the goalbox or until $60 \mathrm{sec}$ elapsed, which resulted in removal from the runway and placement in the goalbox. After $30 \mathrm{sec}$ the goalbox was moved to a holding area for the remainder of a 2-min intertrial interval (ITI). The goalbox was then moved to the start area, and an identical box was placed into the goal area. On all trials except the first, animals were pushed from the box into the start area by use of the rod attached to the movable back wall. Thus, once the animal was first placed in the runway, it was not handled until it was returned to its home cage. The avoidance learning criterion was 8 out of 10 successful avoidance runs on the third pretraining day. Maze training began $24 \mathrm{~h}$ later.

14-unit T-maze training. Maze training began after $20 \mathrm{~min}$ of adaptation to the maze room. A 10-sec shock-avoidance contingency existed in each of the five segments. If the rat failed to cross through the first gate into the first unit within $10 \mathrm{sec}$, a 0.8 -mA scrambled footshock occurred until the animal escaped through the gate, which then was closed. Similarly, the rat had $10 \mathrm{sec}$ to negotiate each of the subsequent segments to avoid shock. The 10-sec avoidance contingency was reset each time the gate closed as the animal entered the next segment in the sequence. Thus, the rat avoided shock by running continuously through the maze. Although errors into culde-sacs were not expressly punished, moving slowly as well as making numerous errors in a segment might result in footshock.

The rat was placed in the start area of the maze on the first trial only. On all subseqeunt trials, the goalbox became the startbox, the animal was pushed into the start area, and an identical box was placed into the goal area. As with pretraining, at the completion of each trial, the rat remained in the goalbox in the goal area for $30 \mathrm{sec}$, the box was moved to a holding area for the remainder of the 2-min ITI, and then it was placed into the start area for the beginning of the next trial. To mask possible odor cues, the grid floor of the maze was wiped with a $95 \%$ ethanol solution during this 2 $\min$ ITI.

Animals received 10 trials on each of 2 consecutive days. Both pretraining and maze training were conducted during the light cycle of the photoperiod from 0900 to $1700 \mathrm{~h}$.

\section{Histology}

Coronal sections of $30 \mu$ cut through the lesion sites were stained with thionin Nissl stain, were viewed through stereo and light microscopes, and were analyzed for damage to specific structures. Drawings showing the site and extent of lesion damage were made from one of every six stained sections using a Bausch and Lomb microprojector. Amount of damage to the FF and adjacent structures was measured and evaluated from these drawings.

\section{Statistical Analyses}

Because sample sizes were small and no significant differences for any performance variable existed between the two control groups according to Mann-Whitney $U$ tests ( $p s>.05$ ), the sham-operated $(n=7)$ and unoperated $(n=6)$ controls were combined into a single control group (CON, $n=13$ ) for subsequent data analyses. Additionally, animals with FF lesions $(n=10)$ were separated from animals with lesions in structures other than the FF $(n=3)$. These 3 animals were dropped from the statistical analyses, and the 10 animals with FF lesions were used as the lesion (LES) group in subsequent data analyses. A 2 (group) $\times 4$ (blocks of five trials) repeated measures analysis of variance (ANOVA) was conducted on each of five separate measures (errors, run time to goal, percent alternation errors, number of shocks, and duration of shock). The response measure, percent alternation error, has been defined elsewhere (Spangler et al., 1986). Essentially, whenever the animal utilized an alternation strategy in a forward-going sequence of responses (at least three turns in the maze) and that sequence of three responses or more resulted in an error, the error was counted as an alternation error. Statistical significance was accepted as $p<.05$.

\section{RESULTS}

\section{Histological Analyses}

Damage to the FF was evident in 10 of the 13 lesioned animals. However, analysis of these 10 brains indicated that the amount of FF damage was greater in 6 of the brains than in the remaining 4 . In these 6 , the FF was severed in the medial lateral directions on many coronal sections, along with considerable damage to the FF in general; there was little or no hippocampal damage; and some damage was found in adjacent structures (thalamus, caudate, corpus callosum, and/or overlying cortex). For the remaining 4 lesioned brains, some damage occurred to the FF along its lateral edge, but the FF was not severed at any point; there was no hippocampal damage; and some damage was found in adjacent structures (thalamus, 
caudate, corpus callosum, and/or overlying cortex). Figure 1 depicts representative sections from brains with large and small FF lesions.

\section{Behavioral Analyses}

Performance in one-way active avoidance pretraining was equivalent between LES and CON groups as all animals met criterion. Percent avoidances across the three sessions were $86 \%$ and $88 \%$ for the CON and FF groups, respectively. Thus, there was no evidence that the FF lesion impaired the ability to learn the avoidance response and to utilize it subsequently in the 14-unit T-maze.

As observed in Figure 2, complex maze performance of the LES group was impaired on all behavioral measures (number of errors, run time to goal, alternation errors, number of shocks, and duration of shock). The repeated measures ANOVAs indicated significant main effects for both group and blocks on all performance variables (all ps < .01). Even though LES animals were poor performers compared with CON animals, they did show learning across trial blocks. However, percentage of alternation errors and number of shocks were two measures wherein the group $\times$ blocks interaction was also significant $[F(3,63)=4.46, p=.006$, and $F(3,63)=6.59$, $p<.001$, respectively]. LES animals showed little improvement in making alternation errors across blocks and were still making this type of error during the last trial block, whereas CON animals showed improvement across blocks to eliminate this response by the last five trials. In contrast, the number of shocks received dropped considerably for the LES group in the last trial block, which reflects learning; that is, on this major performance requirement-run to avoid footshock-the LES rats demonstrated proficiency in the last trial block. Thus,

\section{SMALL LESION}
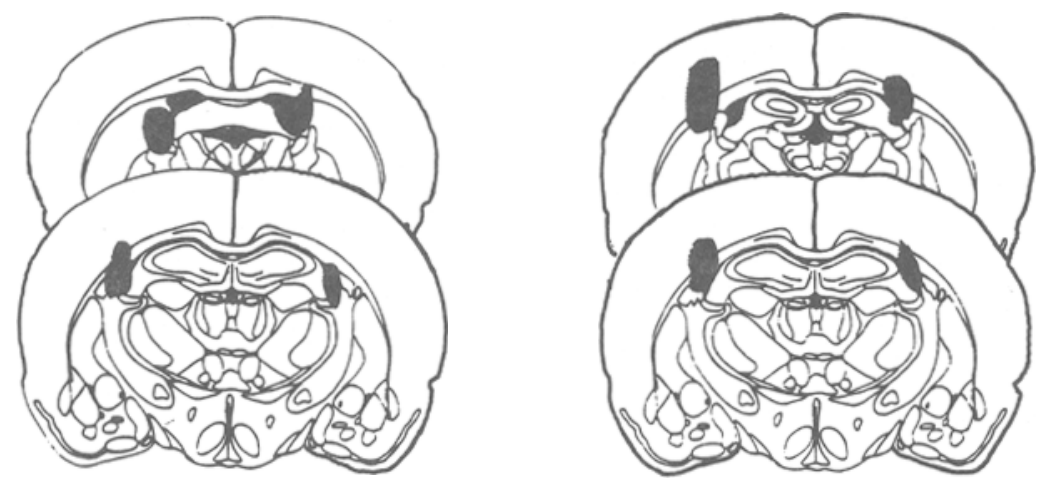

\section{LARGE LESION}
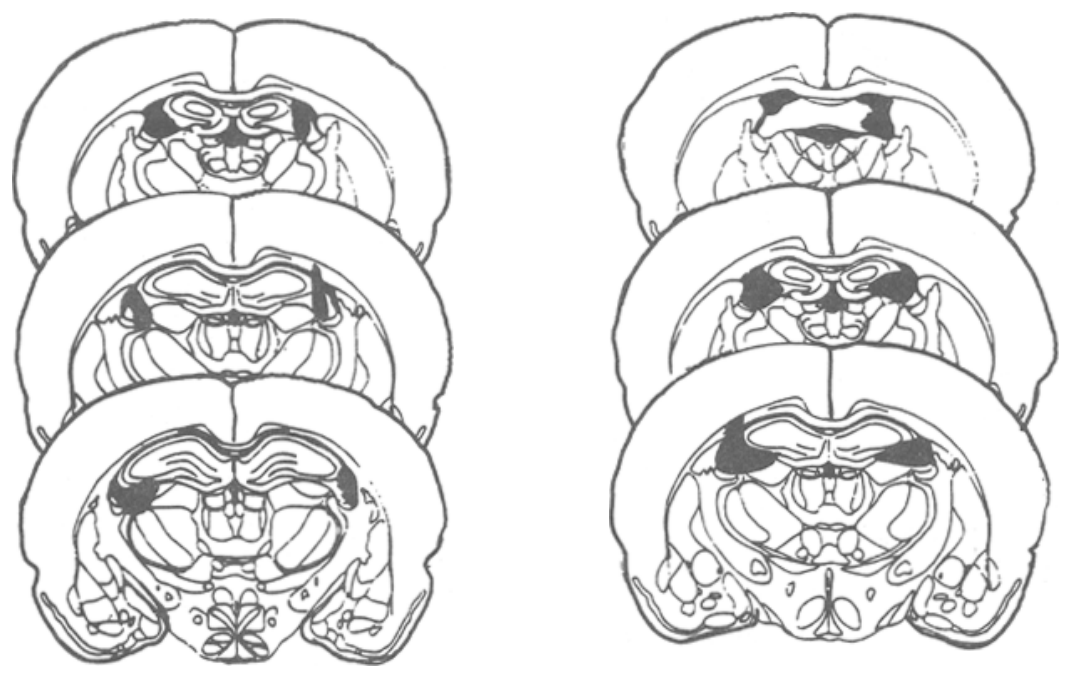

Figure 1. Coronal sections (striped areas indicate lesions) from 4 representative animals, 2 with large and 2 with small fimbria-fornix lesions. Sections were drawn with permission from The Rat Brain in Stereotaxic Coordinates (Figures 17-21) by G. Paxinos and C. Watson, 1982, New York: Academic Press. Copyright 1982 by Academic Press. Reprinted by permission of Harcourt Brace Janovich Group (Australia) Pty Limited, Copyright holder. 

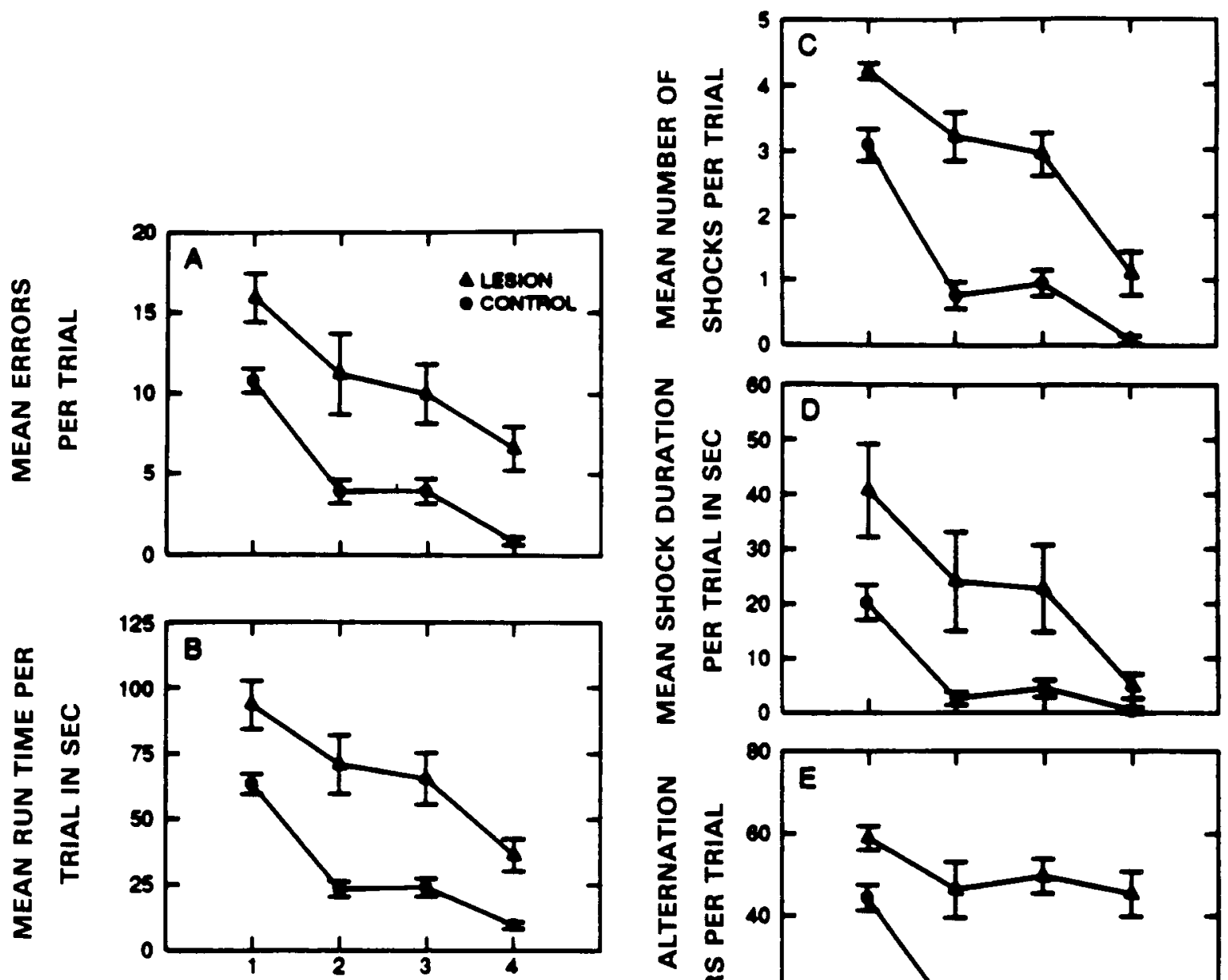

BLOCKS OF FIVE TRIALS
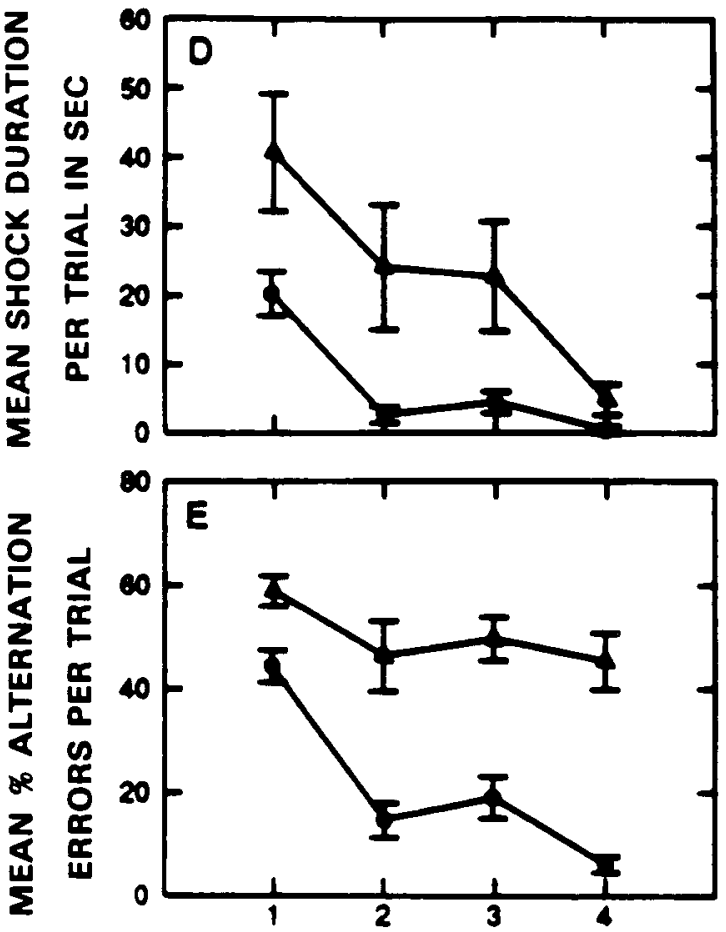

\section{BLOCKS OF FIVE TRIALS}

Figure 2. Per trial means and standard errors for specific performance measures of male F-344 rats in 14-unit T-maze: (A) errors; (B) run time; (C) number of shocks; (D) shock duration; (E) alternation errors.

despite the fact that errors, run time, and shock measures for the LES group were higher than those for the CON group, indicating significant impairment, learning for the LES animals was evidenced across trials, with the exception of one measure, percentage of alternation errors. This response strategy was not eliminated during training.

An additional analysis was conducted to assess more adequately the extent of FF damage in relation to maze performance. The two previously described types of lesions, one large (considerable FF damage and many severed sections) and the second small (with some FF damage and no severed sections), were analyzed further. Data were combined across trial blocks for the control group and for each of the two lesion groups, large-lesion and small-lesion. As presented in Table 1, comparisons on each behavioral measure were made using MannWhitney $U$ tests. Compared with the control animals, large-lesion animals were significantly impaired on all measures of acquisition. This large-lesion group was significantly more impaired than the small-lesion group on four of the five measures. Percent alternation errors for the two lesion groups were similar, which indicates that this measure is sensitive to both small and large lesions. Compared with the control group, the small-lesion group was significantly impaired on three of the five measures, with no differences between the two groups on total errors and shock duration, although total errors did approach significance $(p=.067)$. Overall, it appears that perfor- 
Table 1

Per-Trial Means for Control and Fimbria-Fornix Lesion Groups, with Mann-Whitney $U$ Comparisons Included for Five Maze Performance Measures

\begin{tabular}{lccc}
\hline & \multicolumn{3}{c}{ Group } \\
\cline { 2 - 4 } \multicolumn{1}{c}{ Measure } & $\begin{array}{c}\text { Control } \\
(n=13)\end{array}$ & $\begin{array}{c}\text { Small-Lesion } \\
(n=4)\end{array}$ & $\begin{array}{c}\text { Large-Lesion } \\
(n=6)\end{array}$ \\
\hline Errors & 4.8 & 6.6 & $13.7^{* \dagger}$ \\
Run Time (sec) & 30.0 & $44.8^{*}$ & $80.2^{* \dagger}$ \\
Alternation Errors (\%) & 20.9 & $41.1^{*}$ & $55.3^{*}$ \\
Number of Shocks & 1.4 & $2.3^{*}$ & $3.2^{* \dagger}$ \\
Duration of Shock (sec) & 7.0 & 8.3 & $32.8^{* \dagger}$ \\
\hline
\end{tabular}

*Significantly different from control group, $p<.05$. †Significantly different from small-lesion group, $p<.05$.

mance in this task is susceptible to interference from either small or large FF lesions, but to a much greater extent in the presence of a large lesion where the FF is severed on many sections along this pathway.

\section{DISCUSSION}

The present results clearly demonstrate that bilateral FF lesions impair young rats' acquisition in this shockmotivated 14-unit T-maze. Since there was no apparent difference between the CON and FF groups in avoidance learning during pretraining, the observed impairment was specific to the learning component involved in maze performance. This observation of deficient maze acquisition parallels, first, the age-related impairment previously observed in this task (Goodrick, 1972; Ingram, 1985; Ingram et al., 1987; Michel \& Klein, 1978; Walovitch et al., 1987) and, second, the observed dose-dependent impaired acquisition of young rats in this 14-unit T-maze following systemic injections of the muscarinic antagonist scopolamine (Spangler et al., 1986). Thus, the results from the current lesion study may suggest involvement of the septo-hippocampal cholinergic system for learning and memory in this complex maze; however, these results must be considered with respect to the neuroanatomical and neurochemical specificity of the lesion effect in the present study.

First, we are confident that the observed performance impairment was due to FF damage rather than to damage of adjacent structures. All 3 rats without FF damage that were dropped from the experimental group sustained damage to the caudate nucleus, and performance was comparable to that of CON animals. Five animals in the LES group had some damage to the dorsal and lateral thalamus; however, the remaining LES subjects did not have damage to the thalamus and showed performance impairment. These findings are consistent with those of Olton et al. (1980), who described experiments in which bilateral caudate, neocortical, and amygdala lesions did not affect performance in the radial arm maze, whereas lesions to extrinsic hippocampal connections resulted in chance performance, with no evidence of recovery of function. Thus, concurrent damage to adjacent areas appeared to have no effect on performance.
Second, maze learning ability was related to lesion size in the present study. Impaired acquisition was most evident in rats with large lesions that severed the FF, as manifested by considerable FF damage in many serial sections. All performance measures, including errors, run time, shock number, and duration, were markedly higher in these rats than in those from the CON group or in animals with small lesions. Rats with small lesions, however, still exhibited impairment relative to controls, but primarily in nonassociative measures, such as run time and number of shocks received. Thus, major damage to the FF was associated with a more global impairment in maze performance.

Even with this neuroanatomical evidence of FF lesion specificity, certain limitations apply to implicating the septo-hippocampal cholinergic system in the observed maze learning impairment. First, because markers for cholinergic activity were not used in the present study, no direct assessment of cholinergic involvement in the observed learning deficit could be made. Second, damage to the FF pathway would affect both the hippocampal afferent and efferent fibers (MacLean, 1985). The hippocampal afferents that travel through the fornix arise primarily from the medial septal nucleus, whereas the hippocampal efferents in the FF go to the septum, nucleus accumbens, olfactory tubercle, thalamus, and hypothalamus as well as to the ventral portion of the midbrain central gray (MacLean, 1985). Because of these varied FF projections, it is possible that the observed maze learning impairment may be a result of disruption to hippocampal efferents rather than to disruption of the medial septal hippocampal afferents in this pathway. Furthermore, it has been shown that the more medial cells in the medial septal nucleus project to a segment of the hippocampus that is more proximal to the septum, whereas the more lateral cells of the medial septal nucleus project to a hippocampal segment that is more proximal to the amygdala (MacLean, 1985). Because of the somewhat posteriolateral FF lesion positions in the present study, it is possible that only one part of the medial septal input may have been disrupted, that arising from the lateral cells of the medial septal nucleus.

In addition, results from other studies have questioned the involvement of hippocampal cell populations in specific learning tasks. Jarrard (1986) noted that neurotoxic lesions to the hippocampus had a relatively minor effect on spatial task performance in rats. In that study, removal of the entire hippocampus had less effect on complex spatial memory than did damage to the primary connections of the hippocampus, specifically the FF and the entorhinal cortex.

The results of Knowlton et al.'s (1985) study further complicate the issue of the role played by the septohippocampal cholinergic system in efficient performance in the 14-unit $\mathrm{T}$-maze. Why did we observe impaired performance in this task following FF lesions when the previous investigators did not find such impairment in rats with damage to medial septal cholinergic neurons sending 
fibers to the hippocampus via the FF? Several methodological differences in the studies are apparent. First, the Knowlton et al. paradigm involved food motivation, highly distributed practice (one trial/day), and SpragueDawley rats with neurotoxic lesions in two sites of the basal forebrain cholinergic system, whereas the present study used shock motivation, highly massed practice (10 trials/day), and Fischer-344 rats with lesions only in the FF. Second, there is the issue of lesion magnitude. In our study, lesion size was related to the degree of impairment. In the Knowlton et al. study, cholinergic markers of the lesion were depressed about $31 \%$ in hippocampus, an observation that suggested that some cholinergic input was spared. Thus the discrepant findings between the two studies may be due to the degree to which cholinergic input was spared, or, as previously discussed, an alternative explanation may be that the learning impairment involves disruption of FF fibers other than those from the medial septal area.

Although we are confident of the effects of FF lesions on performance in this task, we remain uncertain of the neuroanatomical locus of this learning impairment. Further experiments in this complex maze with selective lesions to other areas that receive input through the FF are required, as well as studies utilizing neurotoxic lesions specific to cholinergic cells. Studies focusing on the involvement of the medial septal nucleus and specific hippocampal cell populations will be pursued.

The maintenance of an alternation strategy across trials was a prominent feature of maze performance in rats with either small or large FF lesions. Learning was apparent in the LES group, as evidenced by the reduced error rate with increased training, but the percentage of errors resulting from an apparent alternation strategy showed little change across trials among lesioned animals. Control animals did exhibit a marked decline in this strategy. This aspect of performance also parallels observations of the previously mentioned Spangler et al. (1986) scopolamine study, wherein cholinergic blockade through systemic injection of a muscarinic antagonist increased the utilization of an alternation strategy. Interestingly, this strategy represents adaptive responding for rats during early trials in this maze as it can simplify learning, and it appears to be a more prominent strategy of performance among aged animals (Ingram, 1985). However, for rats to learn the correct pathway to the goalbox, this strategy must be abandoned during the course of training. Compared with control animals, rats receiving scopolamine or FF lesions prior to training apparently have more difficulty abandoning the strategy. These observations are consistent with those of Stevens (1981) and Watts, Stevens, and Robinson (1981), who observed the effects of scopolamine upon radial maze performance. Rats with strategies of entering only adjacent arms in the maze were not impaired by scopolamine, but in that case the strategy was highly adaptive throughout training. In the 14-unit T-maze, however, maintaining an initially adaptive alternation strategy throughout training handicaps performance. These obser- vations are also consistent with Winocur and Breckenridge (1973), who observed that hippocampal lesions impaired the performance of rats in a food-motivated sequential maze involving six spatial discriminations. With minimal intramaze and extramaze cues available, the rats relied upon an alternation strategy to learn the maze; however, control groups abandoned this strategy earlier than did hippocampally damaged animals. Perhaps then, interruption of the septo-hippocampal cholinergic system makes the animal revert to or maintain a more simple response strategy that may or may not be adaptive depending upon the task requirements (Soffie, Bronchart, \& LeBailly, 1986). This hypothesis will also require further experimentation with lesions specific to cholinergic systems.

A posteriori we also find our results difficult to reconcile with the working memory/reference memory model of hippocampal function (Walker \& Olton, 1984). Knowlton et al. (1985) classified the 14-unit T-maze as a reference memory task in which learning was not disrupted by neurotoxic lesions to basal forebrain cholinergic systems. Lesions to the FF clearly impaired acquisition in our task. Ingram (1985) argued that information processing that involves both working and reference memory systems must be operational during acquisition of this task. Regarding acquisition of new information, others have questioned the validity of the working memory/reference memory model of hippocampal function. For example, P. D. Gage (1985) observed that hippocampal damage in rats produced impairments in both working and reference memory components of radial arm maze performance when training was initiated postoperatively but did not affect working memory performance when animals had been trained preoperatively. Moreover, it should be recognized that impairments in both working and reference memory components of T-maze performance have been observed previously in aged rats compared with younger counterparts (Lowy et al., 1985).

Whether or not impaired neurotransmission through the FF represents a possible locus of the defective acquisition observed among aged rats in the 14-unit T-maze is an issue that bears further testing. For the present, however, it can be concluded that aging and FF damage produce parallel performance impairment in this complex maze.

\section{REFERENCES}

BARNes, C. A. (1979). Memory deficits associated with senescence: A neurophysiological and behavioral study in the rat. Joumal of Comparative \& Physiological Psychology, 93, 74-104.

Barnes, C. A., MCNaughton, B. L. (1985). An age comparison of rates of acquisition and forgetting of spatial information in relation to long-term enhancement of hippocampal synapses. Behavioral Neuroscience, 99, 1040-1048.

BARTUS, R. T. (1978). Evidence for a direct cholinergic involvement in the scopolamine-induced amnesia by monkeys: Effects of concurrent administration of physostigmine and methylphenidate with scopolamine. Pharmachology, Biochemistry \& Behavior, 9, 833-836.

Bartus, R. T., Dean, R. L., \& Beer, B. (1983). An evaluation of 
drugs for improving memory in aged monkeys: Implications for clinical trials in humans. Psychopharmacological Bulletin, 19, 168-184.

Bartus, R. T., Dean, R. L., Beer, B., \&ippa, A. S. (1982). The cholinergic hypothesis of geriatric memory dysfunction. Science, 217. 408-412.

Bartus, R. T., Dean, R. L., Pontecorvo, J. J., Fucker, C. (1985). The cholinergic hypothesis: A historical overview, current perspectives and future directions. Annals of the New York Academy of Science. 444, 332-358.

COLlerton, D. (1986). Cholinergic function and intellectual decline in Alzheimer's disease. Neuroscience, 19, 1-28.

Coyle, J. T., Price, D. L., DeLong, M. P. (1983). Alzheimer's disease: A disorder of cortical cholinergic innervation. Science, 219. 1184-1190.

GAGE, F. H., \& BjorkLUNd, A. (1986). Cholinergic septal grafts into the hippocampal formation improve spatial learning and memory in aged rats by an atropine-sensitive mechanism. Joumal of Neuroscience, 6, 2837-2847.

GAGE, P. D. (1985). Performance of hippocampectomized rats in a reference/working-memory task: Effect of preoperative versus postoperative training. Physiological Psychology, 13, 235-242.

GoODRICK, C. L. (1968). Learning, retention and extinction of a complex maze habit for mature-young and senescent Wistar albino rats. Joumal of Gerontology, 23, 298-304.

GooDRICK, C. L. (1972). Leaming by mature-young and aged Wistar albino rats as a function of test complexity. Journal of Gerontology. 27, 353-357.

GooDrick, C. L. (1973). Error goal-gradients of mature-young and aged rats during training in a 14-unit spatial maze. Psychological Reports, 32, 359-362.

INGRAM, D. K. (1985). Analysis of age-related impairments in leaming and memory in rodent models. Annals of the New York Academy of Science, 444, 312-331.

INGRAM, D. K., London, E. D., Goodrick, C. L. (1981). Age and neurochemical correlates of radial maze performance in rats. Neurobiology of Aging, 2, 41-47.

Ingram, D., Spangler, E., Freeman, J., Richards, W. (1984). Age differences in performance of rats and mice in a 14-unit $T$-maze. Society of Neuroscience Abstracts, 10, 452.

Ingram, D. K., Weindruch, R., Spangler, E. L., Freeman, J. R., \& WALFORD, R. L. (1987). Dietary restriction benefits learning and motor performance of aged mice. Journal of Gerontology, 42, 78-81.

JARRARD, L. E. (1978). Selective hippocampal lesions: Differential effects on performance by rats of a spatial task with preoperative and postoperative training. Joumal of Comparative \& Physiological Psychology, 92, 1119-1127.

JARRARD, L. E. (1986). Selective hippocampal lesions and behavior: Implications for current research and theorizing. In R. L. Isaacson \& K. H. Pribram (Eds.), The hippocampus (pp. 93-126). New York: Plenum Press.

Knowlton, B. J., Wenk, G. L., Olton, D. S., \& Coyle, J. J. (1985). Basal forebrain lesions produce a dissociation of trial-dependent and trial-independent memory performance. Brain Research, 345, 315-321.
Lowy, A. M., Ingram, D. K., Olton, D. S., Waller. S. B., ReyNolds, M. A., London, E. D. (1985). Discrimination learning requiring different memory components in rats: Age and neurochemical comparisons. Behavioral Neuroscience, 99, 638-651.

MacLean, P. D. (1985). Fiber systems of the forebrain. In G. Paxinos (Ed.), The rat nervous system (Vol. 1, pp. 427-429.). Orlando, FL: Academic Press.

Michel, M. E., Klein, A. W. (1978). Performance differences in a complex maze between young and aged rats. Age, 1, 13-16

Mitchell, S. J., Rawlins, J. A., Steward, O., Olton, D. S. (1982). Modial septal lesions disrupt theta mythm and cholinergic staining in medial entorhinal cortex and produce impaired radial arm maze behavior in rats. Joumal of Neuroscience, 2, 292-302.

Miramoto, M., Kato, J., Narum, S., \& Nagaoka, A. (1987). Characteristics of memory impairment following lesioning of the basal fore brain and medial septal nucleus in rats. Brain Research, 419, 19-31.

Olton, D. S., Becker, J. J., HandelmanN, G. F. (1980). Hip pocampal formation: Working memory or cognitive mapping? Physiological Psychology, 8, 239-246.

Olton, D. S., WAlker, J. A., GAge, F. H. (1978). Hippocampal connections and spatial discrimination. Brain Research, 139, 295-308.

PAxinos, G., \& WAtson, C. (1982). The rat brain in stereotaxic coordinates. New York: Academic Press.

Rapp, P. R., Rosenberg, R. A., Gallagher, M. (1987). An evaluation of spatial information processing in aged rats. Behavioral Neuroscience, 101, 3-12.

Soffie, M., Bronchart, M., LeBailly, B. (1986). The effects of scopolamine on a complex spatial learning. Physiology \& Behavior, 37, 79-84.

SPANGler, E. D., Rigby, P., \& Ingram, D. K. (1986). Scopolamine impairs learning performance of rats in a 14-unit T-maze. Pharmacology, Biochemistry \& Behavior, 25, 673-679.

STEVENS, R. (1981). Scopolamine impairs spatial maze performance in rats. Physiological Psychology, 27, 385-386.

Walker, S. A., Olton, D. S. (1984). Fimbria-fornix lesions impair spatial working-memory but not cognitive mapping. Behavioral Neuroscience, 98, 226-242.

Walovitch, R. C., Ingram, D. K., Spangler, E. L. London, E. D. (1987). Codergocrine, cerebral glucose utilization and maze performance in middle-aged rats. Pharmacology, Biochemistry \& Behavior, 26, 95-101.

Watts, J., Stevens, R., Robinson, C. (1981). Effects of scopolamine on radial maze performance in rats. Physiological Psychology, 26, 845-851.

Winocur, G., Breckenridge, C. B. (1973). Cue-dependent behavior of hippocampally damaged rats in a complex maze. Journal of Comparative \& Physiological Psychology, 82, 512-522.

(Manuscript received October 29, 1987; revision accepted for publication March 22, 1988.) 